\title{
Effects of 5-aza-2'-deoxyctidine on the development of porcine parthenogenetic and nuclear transfer embryos
}

\author{
Yun Fei Diao ${ }^{1}$, Kenji Naruse ${ }^{1}$, Xiao Xia Li ${ }^{1}$, Rong Xun Han ${ }^{1}$, Dong Kyo Kim ${ }^{1,2}$, Tao Lin ${ }^{1}$, \\ Dong II Jin ${ }^{1^{*}}$ \\ ${ }^{1}$ Department of Animal Science and Biotechnology, Research Center for Transgenic Cloned Pigs, Chungnam National University, \\ Daejeon City, South Korea; ${ }^{*}$ Corresponding Author: dijin@cnu.ac.kr \\ ${ }^{2}$ National Institute of Animal Science, Suwon, South Korea
}

Received 20 May 2013; revised 22 June 2013; accepted 1 July 2013

Copyright (C) 2013 Yun Fei Diao et al. This is an open access article distributed under the Creative Commons Attribution License, which permits unrestricted use, distribution, and reproduction in any medium, provided the original work is properly cited.

\section{ABSTRACT}

The current study was to investigate whether embryo or fetal fibroblast cells treated with 5-aza-2'-deoxyctidine (5-aza-dC) have a positive effect on the in vitro development of porcine parthenogenetic and cloned embryos. To this end, porcine fetal fibroblast cells were treated with different concentrations $(5 \mathrm{nM}, 50 \mathrm{nM}$ and 500 nM) of 5-aza-dC for different exposure times (1, 6 and 20 hours), the results showed that DNA methylation in PRE-1 SINE region was gradually reduced over time in cells treated with 5-aza-dC. To determine the effect of 5-aza-dC on in vitro development of porcine activated oocytes, the parthenogenetic embryo was treated with 5-azadC. Notably, treatment with $5 \mathrm{nM}$ 5-aza-dC for 1 hour led to a significant improvement in blastocyst development, compared with the control group. The effects of donor cell treatment with 5-aza-dC on porcine cloned embryos development were further examined by treating fetal fibroblast cells with various concentrations (5 $\mathrm{nM}, 50 \mathrm{nM}$ and $500 \mathrm{nM}$ ) of 5-aza-dC for different exposure times (1, 6 and 20 hours). Exposure of cells in $5 \mathrm{nM} 5$-aza-dC for 1 - 20 hours led to a significant improvement in the percentage of developed blastocysts, while treatment with 500 nM 5-aza-dC did not affect blastocyst development, compared to untreated controls. These findings indicate that treatment of fetal fibroblast cells with relatively low concentrations of 5-aza-dC for short exposure times improves subsequent blastocyst development of porcine cloned embryos.
Keywords: 5-aza-2'-dC; DNA Methylation; Parthenogenetic Embryo; Clone Embryo; In Vitro Development

\section{INTRODUCTION}

Somatic cell nuclear transfer (SCNT) has been successfully employed to generate cloned animals of various species [1]. Porcine cloning via SCNT yielded the first cloned pig in 2000 [2,3]. However, the efficiency of this technique was considered unsatisfactory due to poor in vitro embryonic development and the limited numbers of offspring obtained [4].

Epigenetic modifications, such as DNA methylation and histone acetylation, have been shown to regulate gene expression in higher organisms [5]. Over the course of natural reproduction, DNA methylation levels are relatively low in male and female gametes, which are further demethylated during early embryonic development [6]. During SCNT embryo development, epigenetic remodeling of embryonic chromatin occurs, which includes dramatic changes in DNA methylation and nuclear structure as well as modification of histone tails. Developmental failure of cloned embryos may be predominantly attributed to incomplete epigenetic reprogramming of donor genomic DNA [7,8], and low success rates of cloning and abnormal cloned offspring have been associated with abnormal epigenetic patterns in nuclear transfer (NT) embryos $[5,8]$. The success rate of animal cloning may thus be improved by preventing or reversing epigenetic errors, such as DNA hypermethylation or histone hypoacetylation status $[9,10]$.

Trichostatin A (TSA), a histone deacetylase inhibitor, and 5-aza-2'-deoxycytidine (5-aza-dC), a DNA demethylation agent and inhibitor of DNA methyltransferase ac- 
tivity [11,12], are two widely used agents for epigenetic modification of somatic cells. Previous studies on bovine cloned embryos have reported that treatment of donor cells with TSA and 5-aza-dC, prior to NT, enhances in vitro embryonic development [13,14]. While porcine reconstructed embryos do not display the highly aberrant patterns of methylation seen in IVF embryos, they differ from those of porcine embryos derived in vivo [8]. Two types of genomic regions, centromeric satellites (repeat sequence in a heterochromatic region) and PRE-1 SINE (repeat sequence in a euchromatic region) provide an overview of the DNA methylation status in heterochromatic and euchromatic regions of the genome, respecttively [8]. High concentrations of 5-aza-dC have been shown to be cytotoxic to cancer cells [15] and bovine NT embryos [16], but the low concentration of 5-aza-dC treatment of fibroblast cells (donor cell) may have beneficial effect on the development of porcine cloned embryos. Here, we have established the optimal treatment concentration and exposure time of 5-aza-dC for porcine somatic donor cells, and employed these conditions to determine whether 5-aza-dC can be effectively applied to improve porcine parthenogenetic and cloned embryo development.

\section{MATERIALS AND METHODS}

\subsection{Donor Cell Preparation}

The majority of chemicals used in this study were purchased from Sigma Chemical Co. (St. Louis, MO). Porcine fetuses were obtained from Korean native swine at day 35 of gestation. The heads and internal tissues of fetuses were removed using fine scissors, and the soft tissues (e.g., liver and intestine) discarded. The remaining tissue was cut into small pieces with fine scissors, treated with $0.05 \%$ trypsin and 0.5 mM EDTA (15050065; Gibco, Carlsbad, CA), and subjected to shaking for $10 \mathrm{~min}$ at $38.5^{\circ} \mathrm{C}$ in an incubator. The suspension was centrifuged at $500 \mathrm{rpm}$ for $10 \mathrm{~min}$, and the resulting fetal fibroblast cell pellet washed three times with DMEM. Next, the cell pellet was resuspended in DMEM supplemented with $75 \mu \mathrm{g} / \mathrm{ml}$ penicillin G, $50 \mu \mathrm{g} / \mathrm{ml}$ streptomycin, 5\% (v/v) fetal bovine serum (FBS; Gibco, 16000 $044)$ and $5 \%(\mathrm{v} / \mathrm{v})$ fetal calf serum (FCS; Gibco, 26010 074 ), and cultured at $38.5^{\circ} \mathrm{C}$. All cells were cryopreserved upon reaching confluence. Cells from passages 3 8 were used for nuclear transfer. For experiments, fetal fibroblast cells were grown to $50 \%$ confluence in 12-well plates, treated for 3 min with trypsin EDTA, washed in DMEM, and used as donor cells. Single cells were placed in micromanipulation drops.

\subsection{Preparation of Oocytes}

Porcine ovaries were obtained from prepubertal gilts at a local slaughter house, and transported to the laboratory in PBS solution supplemented with $100 \mathrm{IU} / \mathrm{ml}$ penicillin and $50 \mu \mathrm{g} / \mathrm{ml}$ streptomycin. Cumulus-oocyte complexes (COCs) were collected from $2-6 \mathrm{~mm}$ follicles using a $10 \mathrm{ml}$ syringe fixed with an 18-gauge needle. COCs were washed three times in TL-HEPES containing $0.1 \%(\mathrm{w} / \mathrm{v})$ polyvinyl alcohol (PVA). Oocytes were selected and cultured in TCM-199 (M-4530) supplemented with 10\% (v/v) porcine follicular fluid, $3.05 \mathrm{mM}$ D-glucose, 0.91 $\mathrm{mM}$ sodium pyruvate, $0.57 \mathrm{mM}$ L-cysteine, $0.5 \mu \mathrm{g} / \mathrm{ml}$ LH (L-5269), $0.5 \mu \mathrm{g} / \mathrm{ml} \mathrm{FSH} \mathrm{(F-2293),} 10 \mathrm{ng} / \mathrm{ml}$ epidermal growth factor (E-4127), $75 \mu \mathrm{g} / \mathrm{ml}$ penicillin, 50 $\mu \mathrm{g} / \mathrm{ml}$ streptomycin, and $0.05 \%$ (v/v) MEM vitamins (M-6895). COCs were subsequently transferred to $500 \mu \mathrm{l}$ of maturation medium in a 4-well multidish (Nunc, Roskilde, Denmark) and incubated for 42 to 44 hours at $38.5^{\circ} \mathrm{C}$ in a humid atmosphere containing $5 \% \mathrm{CO}_{2}$. After 22 hours of in vitro maturation, oocytes were washed three times and transferred to $500 \mu \mathrm{l}$ of hormone-free maturation medium for an additional 20 to 22 hours of culture. Following maturation, cumulus cells were removed by repeated pipetting in TL-HEPES supplemented with $0.1 \%$ PVA and $0.3 \%$ hyaluronidase.

\subsection{Oocyte Activation and Culture}

Cumulus-free oocytes were transferred to activation solution $\left(0.3 \mathrm{M}\right.$ mannitol, $1.0 \mathrm{mM} \mathrm{CaCl}{ }_{2} \cdot \mathrm{H}_{2} \mathrm{O}, 0.1 \mathrm{mM}$ $\mathrm{MgCl}_{2} \cdot 6 \mathrm{H}_{2} \mathrm{O}$, and $0.5 \mathrm{mM}$ HEPES), and activated with two DC pulses of $1.1 \mathrm{kV} / \mathrm{cm}$ for $30 \mu$ sec each using a BTX Elector-Cell Manipulator 2001 (BTX, San Diego, CA). Activated embryos were cultured in PZM-3 for 7 days. Parthenogenetic activation experiments were replicated at least three times.

\subsection{Nuclear Transfer and Activation of Embryo Culture}

Nuclear transfer and electrical fusion were conducted as described previously by Naruse, et al. [17] Cumulusfree oocytes were enucleated by aspiration of the first polar body and adjacent cytoplasm with a fine glass pipette in PZM-3 containing $7.5 \mu \mathrm{g} / \mathrm{ml}$ cytochalasin B at $38^{\circ} \mathrm{C}$. A single donor cell was placed in the perivitelline space of each enucleated oocyte. NT embryos were simultaneously fused and activated with two DC pulses of $1.1 \mathrm{kV} / \mathrm{cm}$ for $30 \mu \mathrm{sec}$ in $0.3 \mathrm{M}$ mannitol medium containing $1.0 \mathrm{mM} \mathrm{CaCl} \cdot \mathrm{H}_{2} \mathrm{O}, 0.1 \mathrm{mM} \mathrm{MgCl}{ }_{2} \cdot 6 \mathrm{H}_{2} \mathrm{O}$, and $0.5 \mathrm{mM}$ HEPES. Reconstructed embryos were cultured for 6 days in PZM-3. Nuclear transfer experiments were replicated at least three times.

\subsection{Genomic DNA Isolation and Bisulfite Treatment}

Fetal fibroblast cells were plated on $100 \mathrm{~mm}$ culture 
dishes and grown in DMEM supplemented with 5\% (v/v) FBS and 5\% (v/v) FCS. Cells grown to 50\% confluence were treated with different concentrations $(0,5,50$, and $500 \mathrm{nM})$ of 5 -aza-dC for various exposure times $(0,1,6$, and $20 \mathrm{~h}$ ). Genomic DNA was isolated from treated cells, and $1 \mu \mathrm{g}$ of purified DNA subjected to sodium bisulfate-treatment for 24 hours using an MSP kit (In2 Gen Co. Ltd., Seoul, Korea). Bisulfite-treated genomic DNA was purified with the MSP kit, precipitated with ethanol, and resuspended in $25 \mu$ l of diluted water.

The centromeric satellite and PRE-1 SINE sequences were obtained from GenBank (Z75640, X64127, Y00104, and AJ251914) and primers designed to amplify the desired fragments (centromeric satellite DNA,

5'-TTTGTAGAATGTAGTTTTTTAGAAG-3' and 5'-AAAATCTA AACTACCTCTAACTC-3'; PRE-1, 5'-TTAACRAATCCRACTAAAAACCATA-3' and 5'-GTTGGTTTATMTTAGAGTTATAGTAA-3') (Kang, et al. 2001; Archer, et al. 2003). PCR conditions consisted of 40 cycles of $94^{\circ} \mathrm{C}$ for $2 \mathrm{~min}, 94^{\circ} \mathrm{C}$ for $60 \mathrm{sec}$, $55^{\circ} \mathrm{C}$ for $60 \mathrm{sec}$ and $72^{\circ} \mathrm{C}$ for $60 \mathrm{sec}$, followed by final elongation of $72^{\circ} \mathrm{C}$ for $10 \mathrm{~min}$ [18].

Amplified products were ligated into pGEM-T plasmid vectors using the pGEMP ${ }^{\circledR} \mathrm{P}-\mathrm{T}$ Easy Vector System (Promega, USA), and 20 subclones picked and sequenced using an automatic sequencer (Applied Biosystems, PRISM 377).

\subsection{Experimental Design}

For DNA methylation analysis, growing porcine fetal fibroblast cells were treated with 5-aza-dC at different concentrations $(5,50$, or $500 \mathrm{nM})$ and exposure times $(0$, 1,6 , and 20 hours), prior to bisulfite treatment.

For parthenogenetic activation experiments designed to investigate the effects of different concentrations of 5aza-dC on the in vitro development of activated porcine oocytes, cumulus-free oocytes were electrically activated with a two DC pulse $(1.1 \mathrm{kV} / \mathrm{cm}, 30 \mu \mathrm{sec})$. Activated oocytes were treated with $0,2.5,5,50$ or 500 nM 5-aza$\mathrm{dC}$ for 1 hour, and cultured in PZM-3 for 7 days.

For nuclear transfer experiments designed to establish the effects of different concentrations of 5-aza-dC over variable exposure times on the in vitro development of reconstructed embryos after NT, growing porcine fetal fibroblast cells were treated with $0,5,50$, and $500 \mathrm{nM}$ 5-aza-dC for 1 hour; with 5 nM 5-aza-dC for $0,1,6$, and 20 hours; with 50nM for 6, 20 hours. Thereafter, enucleated oocytes were reconstructed with 5-aza-dC-treated fetal fibroblast cells, fused with two DC pulses (1.1 $\mathrm{kV} / \mathrm{cm}, 30 \mu \mathrm{sec}$ ), and cultured in PZM-3 for 6 days. Cleavage and blastocyst formation rates were evaluated under a stereomicroscope on days 3 and 6 of culture. Blastocysts were stained with Hoechst 33342, and the number of nuclei examined using fluorescence micros- copy (Olympus, Japan).

\subsection{Statistical Analysis}

All data are expressed as mean \pm standard error (SE) and repeat at least 3 times. Significant differences among treatment groups were determined with ANOVA using the GLM procedure of SAS (SAS Institute Inc., Cary, NC, USA) and Duncan's multiple range test after analysis of variance. Statistical significance was determined as $\mathrm{P}$ values less than 0.05 .

\section{RESULTS}

\subsection{Effect of 5-aza-dC Treatment on the DNA Methylation Status}

The methylation status of centromeric satellite and PRE-1 SINE sequences was determined in 5-aza-dCtreated fetal fibroblast cells (Figures 1 and 2). The centromeric satellite sequences of fetal fibroblast cells treated with 5 or $50 \mathrm{nM} 5$-aza-dC for 1 to 20 hours displayed no changes in methylation, compared to untreated controls (Figure 1(a)). In the PRE-1 sequences, DNA methylation levels were gradually reduced with longer exposure to 5-aza-dC (Figure 2(a)). DNA methylation levels of the PRE-1 sequences in $5 \mathrm{nM} 5$-aza-dC-treated groups were comparable to those of $50 \mathrm{nM} 5$-aza-dCtreated groups for 1 and 6 hours. In the $50 \mathrm{nM}$ 5-aza-dCtreated groups, DNA methylation was significantly decreased at 20 hours exposure.

\subsection{Effect of 5-aza-dC Treatment on the Development of Porcine Parthenogenetic Embryo}

Next, we performed parthenogenetic activation experiments in which mature oocytes were subjected to electric activation, followed by treatment with 2.5 to $500 \mathrm{nM}$ 5-aza-dC. Our preliminary findings revealed that embryo exposure to 5-aza-dC for longer than $1 \mathrm{~h}$ induced a decrease in blastocyst development rate (data not shown). Upon exposure of activated oocytes to different 5-aza-dC concentrations ( 2.5 to $500 \mathrm{nM}$ ) for 1 hour, we observed no significant differences in cleavage rates between the 5-aza-dC-treated and control groups. However, embryos treated with $5 \mathrm{nM}$ 5-aza-dC showed significantly higher blastocyst development rates, compared with the control, $50 \mathrm{nM}$ and $500 \mathrm{nM}$ treatment groups. The blastocyst development rate of the $5 \mathrm{nM}$ treatment group was slightly higher than $2.5 \mathrm{nM}$ treatment, but this difference did not reach the level of statistical significance (Table 1).

\subsection{Development of Cloned Embryo Derived from Donor Cell Treated with 5-aza-dC}

In NT experiments performed to examine the effects 


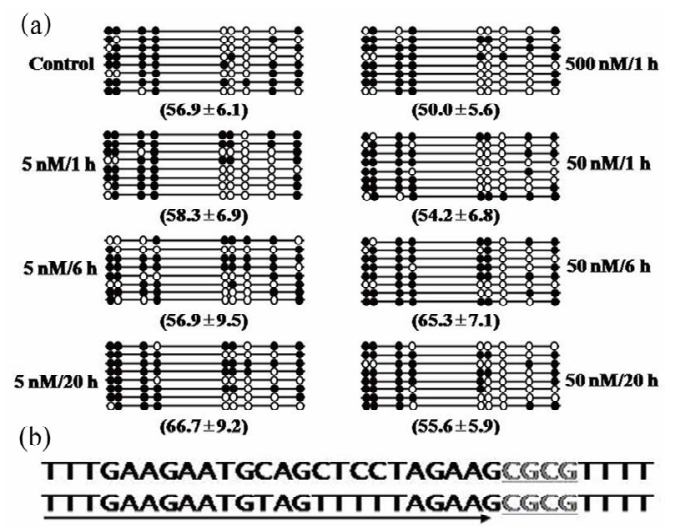

GTGCCGTITCGGAGCTAGGCCTGAGGTGGGTC GTGTCGTTTCGGAGTTAGGTTTGAGGTGGTT

ССTСССТAGCTGGCTCTGGGGGGGTTGCTAGC TITTITAGTTGGTITTGGGGGGGTTGTTAGT

TCCAGTGCACACAGGGCI TCT TCATGCCAAAT TITAGTGTATATAGGGTTTTTTATGTTAAAT

CAGCCTTCTGCGCGAAGGAGAAGACGTITGGA TAGTITITTGCGCGAAGGAGAAGACGTITGGA

TTTGGgTTCCAGCTGCGGAGATCACCAGGCA TTTGGGTTTTAGTTGCGGAGATTATTAGGTAA

GCAGCAGTGCCCACGGAGCCAGAGGCAGCCCA GTAGTAGTGTTTACGGAGTTAGAGGTAGTTTA

\section{GACCCT}

GATTTT

Figure 1. Methylation patterns of the centromeric satellite region. a) The methylation status of a satellite DNA sequence was examined in porcine fetal fibroblast cells treated with 5 -aza-dC at different concentrations (0, 5, 50, and $500 \mathrm{nM})$ and exposure times $(0,1,6$, and $20 \mathrm{~h})$. The $\mathrm{CpG}$ methylation status was analyzed using bisulfite sequencing. Open circle, unmethylated CpG site; closed circle, methylated CpG site. The percentage of methylation was calculated from the total number of methylated sites. The overall percentage of methylation expressed as mean $\pm \mathrm{SE}$ is shown below each group. There were no significant differences among all groups. b) Conserved CpGs present in the centromeric satellite region. Arrows: primers.

of different concentrations of 5-aza-dC on NT embryo development, fetal fibroblast cells were treated with 0,5 , 50, $500 \mathrm{nM}$ 5-aza-dC for 1 hour, and used to reconstruct embryos. Cleavage rates and total cell numbers of blastocysts were not significantly different between the 5aza-dC-treated and control groups of fetal fibroblast cells exposed to different concentrations of 5-aza-dC for 1 hour. However, fetal fibroblast cells treated with $5 \mathrm{nM}$ or $50 \mathrm{nM}$ 5-aza-dC for $1 \mathrm{~h}$ showed significantly higher blastocyst formation rates $(p<0.05)$ compared with the control group, whereas exposure to $500 \mathrm{nM} 5$-aza-dC could not improve blastocyst formation rate (Table 2).

To examine the effects of concentrations and expo-

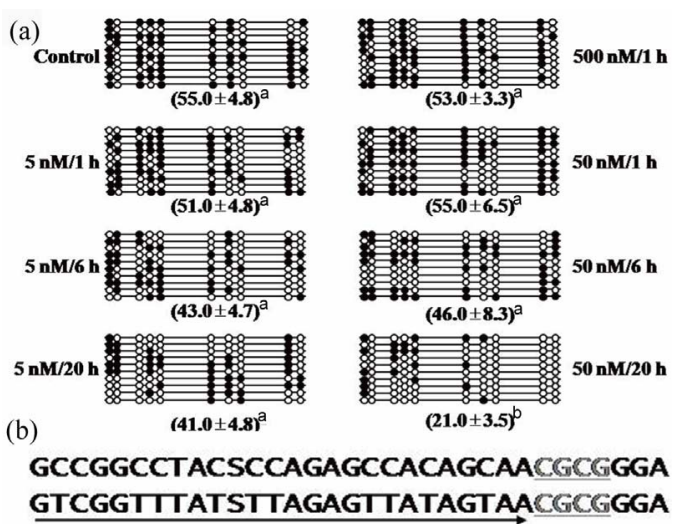

TCCGAGCGGCGTCTGBSACCTACACCACAGCTC
TTCGAGCGGCGTTTGBSATTTATATTATAGTTT

ACGGCAABGCCGGATCGTTAACCCACTGAGCAA ACGGTAABGTCGGATCGTTAATTTATTGAGTAA

GGSCAGGGATCGAACCCGCAACCTCATGGTTCC GGSTAGGGATCGAATTCGTAATTTATGGTTा

\section{TAGTCGGATTCGTTAA}

TAGTCGGATTCGTTAA

Figure 2. Methylation patterns of the PRE-1 SINE region. (a) The methylation status of the PRE-1 SINE sequence was examined in porcine fetal fibroblast cells treated with 5-aza-dC at different concentrations $(0,5,50$, and $500 \mathrm{nM})$ and exposure times $(0,1,6$, and $20 \mathrm{~h})$. The CpG methylation status was analyzed using bisulfite sequencing. Open circle, unmethylated CpG site; closed circle, methylated CpG site. The overall percentage of methylation expressed as mean \pm SE. is shown below each group. ${ }^{\mathrm{a}, \mathrm{b}}$ Values in the same column with different superscripts are significantly different $(\mathrm{P}<0.05)$. (b) Conserved CpGs present in the PRE-1 SINE region. Arrows: primers.

Table 1. Effects of different concentrations of 5-aza-dC on in vitro development of porcine parthenogenetic embryos.

\begin{tabular}{ccccc}
\hline $\begin{array}{c}\text { Treatment } \\
(\mathrm{nM})^{1}\end{array}$ & $\mathrm{~N}^{2}$ & $\begin{array}{c}\text { Cleavage rate } \\
\%(\mathrm{n})\end{array}$ & $\begin{array}{c}\text { Blastocyst rate } \\
\%(\mathrm{n})\end{array}$ & $\begin{array}{c}\text { Total no. cells in } \\
\text { blastocysts }\end{array}$ \\
\hline 0 & 120 & $80.0 \pm 5.6(96)$ & $17.5 \pm 2.6(21)^{\mathrm{a}}$ & $35.1 \pm 4.3$ \\
2.5 & 106 & $80.2 \pm 6.2(85)$ & $19.8 \pm 1.2(21)^{\mathrm{ab}}$ & $35.9 \pm 3.7$ \\
5 & 114 & $79.0 \pm 3.4(90)$ & $28.9 \pm 1.2(33)^{\mathrm{b}}$ & $35.2 \pm 2.8$ \\
50 & 116 & $82.0 \pm 2.5(95)$ & $18.1 \pm 3.4(21)^{\mathrm{a}}$ & $36.8 \pm 3.5$ \\
500 & 116 & $79.3 \pm 2.9(92)$ & $14.7 \pm 0.5(17)^{\mathrm{a}}$ & $32.5 \pm 3.4$ \\
\hline
\end{tabular}

Percentages and cell numbers are expressed as mean \pm SE from four experiments. ${ }^{1}$ Porcine activated embryos were treated with various doses $(0$, $2.5,5,50$, and $500 \mathrm{nM}$ ) of 5 -aza-dC for 1 hour after electrical activation. ${ }^{2}$ Number of parthenogenetic embryos cultured.

suretimes of 5-aza-dC on NT embryo development, fetal fibroblast cells used for NT were treated with $5 \mathrm{nM}$ 5-aza-dC for 0, 1, 6 and 20 hours, and 50 nM 5-aza-dC for 6 and 20 h. Notably, fetal fibroblast cells treated with $5 \mathrm{nM} 5$-aza-dC for 1 to 20 hours showed significantly higher blastocyst development rates ( $<<0.05$ ), compared 
Table 2. Effects of 5-aza-dC treatment of fetal fibroblast cells on subsequent in vitro development of porcine nuclear transfer embryos.

\begin{tabular}{cccccc}
\hline Treatment (nM) & $\mathrm{N}^{2}$ & Fusion rate Mean\% (n) & Cleavage rate Mean\% (n) & Blastocyst rate Mean\% (n) & Total no. cells in blastocysts \\
\hline 0 & 95 & $86.3 \pm 1.7(82)$ & $77.9 \pm 2.2(74)$ & $12.6 \pm 0.9(12)^{\mathrm{a}}$ & $29.8 \pm 0.9$ \\
5 & 91 & $90.1 \pm 2.2(82)$ & $81.3 \pm 3.3(74)$ & $23.1 \pm 2.6(21)^{\mathrm{b}}$ & $31.8 \pm 2.5$ \\
50 & 92 & $85.9 \pm 2.3(79)$ & $81.5 \pm 6.1(75)$ & $20.7 \pm 0.9(19)^{\mathrm{bc}}$ & $29.3 \pm 1.6$ \\
500 & 87 & $88.5 \pm 2.5(77)$ & $74.7 \pm 1.1(65)$ & $13.8 \pm 0.9(12)^{\mathrm{ac}}$ & $27.5 \pm 2.0$ \\
\hline
\end{tabular}

Percentages and cell numbers are expressed as mean \pm SE from four replicate experiments. ${ }^{1}$ Fetal fibroblast cells were treated with various doses $(0$, 5 , 50 , and $500 \mathrm{nM}$ ) of 5-aza-dC for 1 hour before NT. ${ }^{2}$ Number of reconstructed embryos cultured. ${ }^{\text {a,b }}$ Values in the same column with different superscripts are significantly different $(\mathrm{P}<0.05)$.

Table 3. In vitro development of porcine nuclear transfer embryos derived from fetal fibroblasts after treatment with 5-aza-dC at different concentrations and exposure times.

\begin{tabular}{clcccc}
\hline Treatment $(\mathrm{nM})^{1}$ & $\mathrm{~N}^{2}$ & Fusion rate \% (n) & Cleavage rate \% (n) & Blastocyst rate \% (n) & Total no. cells in blastocysts \\
\hline control & 80 & $80.0 \pm 2.2(64)$ & $62.5 \pm 1.3(50)$ & $12.5 \pm 1.4(10)^{\mathrm{a}}$ & $28.1 \pm 1.4$ \\
$5 / 1$ & 85 & $87.1 \pm 2.0(74)$ & $63.5 \pm 2.2(54)$ & $21.2 \pm 1.5(18)^{\mathrm{b}}$ & $29.1 \pm 1.8$ \\
$5 / 6$ & 81 & $84.0 \pm 3.6(68)$ & $63.0 \pm 2.2(51)$ & $18.5 \pm 1.1(15)^{\mathrm{bc}}$ & $28.6 \pm 1.4$ \\
$5 / 20$ & 80 & $81.3 \pm 3.0(65)$ & $66.3 \pm 4.4(53)$ & $20.0 \pm 0.4(16)^{\mathrm{bc}}$ & $28.8 \pm 1.4$ \\
$50 / 6$ & 82 & $85.4 \pm 2.8(70)$ & $65.9 \pm 3.1(54)$ & $14.6 \pm 1.9(12)^{\mathrm{ac}}$ & $27.0 \pm 1.6$ \\
$50 / 20$ & 96 & $84.4 \pm 0.9(81)$ & $67.7 \pm 3.3(65)$ & $8.3 \pm 1.3(8)^{\mathrm{a}}$ & $27.3 \pm 1.5$ \\
\hline
\end{tabular}

Percentages and cell numbers are expressed as mean \pm SE from three replicate experiments. ${ }^{1}$ Fetal fibroblast cells were treated with $5 \mathrm{nM} 5$-aza-dC of different exposure times $\left(0,1,6,20\right.$ hours) and with $50 \mathrm{nM} 5$-aza-dC for 6 or 20 h before NT. ${ }^{2}$ Number of reconstructed embryos cultured. ${ }^{\mathrm{a}-\mathrm{c}}$ Values in the same column with different superscripts are significantly different $(\mathrm{P}<0.05)$.

with the control group (Table 3). Treatment group with 5nM 5-aza-dC for 1 hour had the highest blastocyst formation rate. When the fetal fibroblast cells treated with $50 \mathrm{nM} 5$-aza-dC for 6 or 20 hours, the blastocyst formation rate were not significantly increased compared with control group. We observed no significant differences in the cleavage rates and total cell number of blastocysts between the 5-aza-dC-treated and control groups.

\section{DISCUSSION}

DNA methylation in mammals is an essential process in the regulation of transcription during embryonic development [8]. However, epigenetic modification of DNA methylation in mammals occurs aberrantly in most cloned embryos $[19,20]$. In particular, DNA methylation and histone acetylation errors [18] and incomplete reprogramming following nuclear transfer [21] are thought to contribute significantly to the low efficiency of somatic cell cloning. In a previous study, treatment with the histone deacetylase inhibitor, TSA, increased the success rate of mouse and porcine cloning, supporting the importance of epigenetic status in the development of cloned embryos [22,23].

Methylation status has been analyzed in cloned porcine [8] and bovine embryos [18] using bisulfite treatment, followed by methyl-sensitive PCR. Analysis of centromeric satellite DNA sequences in bovine normal and cloned blastocysts revealed increased methylation levels in a significant number of cloned embryos. Addi- tionally, Kang, et al. (2001) reported that the centromeric satellite DNA sequences of porcine fetal fibroblast donor cells are hypermethylated. This status was retained through the 4 - 8 cell stage when normal development requires demethylation [6]. Analogous results were obtained with the PRE-1 SINE euchromatin sequence [8]. These findings indicate that DNA sequences of porcine SCNT embryos undergo preimplantation demethylation in a manner similar to that in embryos in vivo.

The present study was designed to investigate the DNA methylation status of 5-aza-dC-treated porcine fetal fibroblast cells in representative heterochromatin and euchromatin sequences, and establish whether 5-aza-2'$\mathrm{dC}$ treatment improves the developmental rate of porcine parthenogenetic and cloned embryos.

Treatment with $50 \mathrm{nM}$ 5-aza-dC for 20 hours led to a significant reduction in the DNA methylation levels of the PRE-1 sequence, but not that of the centromeric satellite sequence (Figures 1 and 2), suggesting that euchromatic regions are susceptible to alterations in the DNA methylation state. Moreover, methylation analysis of DNA obtained from 5-aza-dC-treated fetal fibroblast cells showed that longer durations of exposure influenced the DNA methylation status in the PRE-1 sequence, but not the centromeric sequence.

In parthenogenetic activation experiments, treatment of porcine activated oocytes with low concentrations of 5-aza-dC for 1 hour improved the blastocyst development rate (Table 1), whereas higher concentrations of 
5-aza-dC were relatively ineffective and/or even detrimental to further in vitro development. These results suggest that exposure of activated oocytes to $5 \mathrm{nM} 5$-azadC for 1 hour promotes further development by triggering adjustment of methylation status without injuring cells. Consistent with this hypothesis, our NT experiments disclosed improved blastocyst development of porcine cloned embryos in cases where donor cells were treated with $5 \mathrm{nM} 5$-aza-dC for 1 to 20 hours (Table 3). In contrast, elevated concentrations of 5-aza-dC (50 nM or higher) had detrimental effects on reconstructed embryos (Table 2). Based on these findings, we suggest that brief exposure of fetal fibroblasts to $5 \mathrm{nM} 5$-aza-dC safely facilitates the reprogramming of methylation patterns with lower toxicity after nuclear transfer, leading to improvement of blastocyst development. In mammalian somatic cells, genomic methylation patterns are regulated by DNA methyltransferase-1 (Dnmt1). Preimplantation embryos lack Dnmt1, but express a corresponding protein designated Dnmt1o (Yu, et al. 2009), which is synthesized and stored in the cytoplasm of oocytes and all preimplantation cleavage NT. Yu and colleagues showed that in mouse IVF embryos treated with 5-aza-dC during the preimplantation stage, nuclear Dnmt1o protein is lost at the 8-cell stage, leading to a decrease in DNA methyllation [24]. In normal IVF embryos, de novo methylation seems to occur at the 8-cell stage, and decreased DNA methylation at this stage may lead to developmental arrest of the embryo. Thus the 5-aza-dC treatment time is critical, and long-term treatment of preimplantation embryos may be not beneficial for development. Tsuji and co-workers [25] showed that long-term treatment of mouse NT embryos with 5-aza-dC did not improve development, possibly associated with aberrant loss of Dnmt1o in 8-cell embryos. In the current study, we treated donor cells with 5-aza-dC and reconstructed NT embryos in a manner beneficial to development. These short time treatments could not only avoid the aberrant loss of Dnmt1o in 8-cell embryos, but also could alter the DNA methylation status of the donor cells for nuclear reprogramming during the nuclear transfer. Notably, exposure of donor cells to low concentrations of 5-aza-dC over short-term periods led to improvements in reconstructed NT embryo development. One possible reason is that high concentrations of 5-aza-dC and long-term treatment are highly toxic for donor cells, and therefore harmful for NT embryo development. Alternatively, development of NT embryos may not require significant demethylation in donor cells prior to NT. After nuclear transfer, the reconstructed embryo may additionally demethylate DNA of nuclei derived from donor cells. Thus, the donor cell may be partially methylated before NT to a sufficient extent for NT embryo development.

\section{CONCLUSION}

We have provided evidence that a brief, low-dose and short-term treatment of porcine fetal fibroblasts with 5-aza-dC aids in improving the efficiency of the somatic cell nuclear transfer procedures. Further studies are required to determine the normal epigenetic status for porcine early embryonic development and how this condition could be experimentally induced in NT embryos.

\section{ACKNOWLEDGEMENTS}

This work was supported by the BioGreen 21 Program of the Rural Development Administration (grant no. PJ009060) and the Bio-industry Technology Development Program (grant no. IPET312060-5) of the Ministry for Food and Agriculture, Republic of Korea.

\section{REFERENCES}

[1] Li, X., Li, Z., Jouneau, A., Zhou, Q. and Renard, J.P. (2003) Nuclear transfer: Progress and quandaries. Reproductive Biology Endocrinology, 1, 84.

[2] Onishi, A., Iwamoto, M., Akita, T., Mikawa, S., Takeda, K., Awata, T., Hanada, H. and Perry, A.C.F. (2000) Pig cloning by microinjection of fetal fibroblast nuclei. Science, 289, 1188-1190. doi:10.1126/science.289.5482.1188

[3] Polejaeva, I.A., Chen, S.H., Vaught, T.D., Page, R.L., Mullins, J., Ball, S., Dai, Y., Boone, J., Walker, S., Ayares, D.L., Colman, A. and Campbell, K.H. (2000) Cloned pigs produced by nuclear transfer from adult somatic cells. Nature, 407, 86-90. doi:10.1038/35024082

[4] Pratt, S.L., Sherrer, E.S., Reeves D.E., Stice S.L. (2006) Factors influencing the commercialisation of cloning in the pork industry. Society of Reproduction and Fertility supplement, 62, 303-315.

[5] Rideout W.M. 3rd, Eggan, K. and Jaenisch, R., (2001) Nuclear cloning and epigenetic reprogramming of the genome. Science, 293, 1093-1098. doi:10.1126/science.1063206

[6] Kang, Y.K., Koo, D.B., Park, J.S., Choi, Y.H., Kim, H.N., Chang, W.K., Lee, K.K. and Han, Y.M. (2001) Typical demethylation events in cloned pig embryos. Clues on species-specific differences in epigenetic reprogramming of a cloned donor genome. Journal of Biological Chemistry, 276, 39980-39984. doi:10.1074/jbc.M106516200

[7] Wilmut, I., Beaujean, N., De Sousa, P.A., Dinnyes, A., King, T.J., Paterson, L.A., Wells, D.N. and Young, L.E. (2002) Somatic cell nuclear transfer. Nature, 419, 583587. doi:10.1038/nature01079

[8] Han, Y.M., Kang, Y.K., Koo, D.B. and Lee, K.K. (2003) Nuclear reprogramming of cloned embryos produced in vitro. Theriogenology, 59, 33-44. doi:10.1016/S0093-691X(02)01271-2

[9] Yamanaka, K., Sakatani, M., Kubota, K., Balboula, A.Z., Sawai, K. and Takahashi, M. (2011) Effects of downregulating DNA methyltransferase 1 transcript by RNA interference on DNA methylation status of the satellite I 
region and in vitro development of bovine somatic cell nuclear transfer embryos. Journal of Reproduction and Development, 57, 393-402. doi:10.1262/jrd.10-181A

[10] Liu, L.M., Liu, Y., Gao, F., Song, G.Q., Wen, J., Guan, J.Y., Yin, Y.P., Ma, X., Tang, B. and Li, Z.Y. (2012) Embryonic Development and Gene Expression of Porcine SCNT Embryos Treated With Sodium Butyrate. Journal of Experimental of Zoology Part B: Molecular and Development Evolution, 318, 224-234 doi:10.1002/jez.b.22440

[11] Enright, B.P., Kubota, C., Yang, X. and Tian, X.C. (2003) Epigenetic Characteristics and development of embryos cloned from donor cells treated by trichostatin A or 5-aza-2'-deoxycytidine. Biology of Reproduction, 69, 896-901. doi:10.1095/biolreprod.103.017954

[12] Enright, B.P., Sung, L.Y., Chang, C.C., Yang, X. and Tian, X.C. (2005) Methylation and acetylation characteristics of cloned bovine embryos from donor cells treated with 5-aza-2'-deoxycytidine. Biology of Reproduction, 72, 944948. doi:10.1095/biolreprod.104.033225

[13] Ding, X., Wang, Y., Zhang, D., Wang, Y., Guo, Z. and Zhang, Y. (2008) Increased pre-implantation evelopment of cloned bovine embryos treated with 5-aza-2'-deoxycytidine and trichostatin A. Theriogenology, 70, 622-630. doi:10.1016/j.theriogenology.2008.04.042

[14] Wang, Y.S., Su, J.M., Wang, L.J., Xu, W.B., Quan, F.S., Liu, J. and Zhang, Y. (2011) The effects of 5-aza-2'-deoxycytidine and trichostatin a on gene expression and DNA methylation status in cloned bovine blastocysts. Cell Reprogram, 13, 297-306. doi:10.1089/cell.2010.0098

[15] Lyko, F. and Brown, R. (2005) DNA methyltransferase inhibitors and development of epigenetic cancer therapies. Journal of National Cancer Institute, 97, 1498-1506. doi:10.1093/jnci/dji311

[16] Tian, X.C., Kubota, C., Enright, B. and Yang, X. (2003) Cloning animals by somatic cell nuclear transfer-biological factors. Reproductive Biology and Endocrinology, 1, 98. doi:10.1186/1477-7827-1-98

[17] Naruse, K., Quan, Y.S., Kim, B.C., Lee, J.H., Park, C.S. and Jin, D.I. (2007) Brief exposure to cycloheximide prior to electrical activation improves in vitro blastocyst development of porcine parthenogenetic and reconstructed embryos. Theriogenology, 68, 709-716. doi:10.1016/j.theriogenology.2007.05.065

[18] Kang, Y.K., Koo, D.B., Park, J.S., Choi, Y.H., Chung, A.S., Lee, K.K. and Han, Y.M. (2001) Aberrant methylation of donor genome in cloned bovine embryos. Nature Genetics, 28, 173-177. doi:10.1038/88903

[19] Bird, A.P. and Wolffle, A.P. (1999) Methylation-induced repression-belts, braces, and chromatin. Cell, 99, 451-454. doi:10.1016/S0092-8674(00)81532-9

[20] Bestor, T.H. (2000) The DNA methyltransferases of mammals. Human Molecular Genetics, 9, 2395-2402. doi:10.1093/hmg/9.16.2395

[21] Dean, W., Santos, F., Stojkovic, M., Zakhartchenko, V., Walter, J., Wolf, E. and Reik, W. (2001) Conservation of methylation reprogramming in mammalian development: Aberrant reprogramming in cloned embryos. Proceedings of the National Academy of Sciences of the United States of America, 98, 13734-13738. doi:10.1073/pnas.241522698

[22] Kishigami, S., Mizutani, E., Ohta, H., Hikichi, T., Thuan, N.V., Wakayama, S., Bui, H.T. and Wakayama, T. (2006) Significant improvement of mouse cloning technique by treatment with trichostatin A after somatic nuclear transfer. Biochemical and Biophysical Research Communications, 340, 183-189. doi:10.1016/j.bbrc.2005.11.164

[23] Zhang, Y., Li, J., Villemoes, K., Pedersen, A.M., Purup, S. and Vajta, G. (2007) An epigenetic modifier results in improved in vitro blastocyst production after somatic cell nuclear transfer. Cloning and Stem Cells, 9, 357-363. doi:10.1089/clo.2006.0090

[24] Yu, J.N., Xue, C.Y., Wang, X.G., Lin, F., Liu, C.Y., Lu, F.Z. and Liu, H.L. (2009) 5-aza-2'-deoxycytidine (5-AZA-CdR) leads to down-regulation of Dnmt1o and gene expression in preimplantation mouse embryos. $Z y$ gote, 17, 137-145. doi:10.1017/S0967199408005169

[25] Tsuji, Y.T., Kato, Y.K. and Tsunoda, Y.K. (2009) The developmental potential of mouse somatic cell nucleartransferred oocytes treated with trichostatin $\mathrm{A}$ and 5-aza-2'-deoxycytidine. Zygote, 17, 109-115. doi:10.1017/S0967199408005133 